\title{
Symposia on e-Health - Opportunities and Challenges
}

Dr. Clive C. James MD, MSc

Medical Officer (Health Informatics), Office of the Deputy Director General Health Services (Planning),

Ministry of Health, Sri Lanka

E-Mail address: clive.jms@gmail.lk

Sri Lanka Journal of Bio-Medical Informatics 2012;3(4):123-126

doi: http://dx.doi.org/10.4038/sljbmi.v3i4.4789

Keeping in line with the vision of the Sri Lanka Medical Association (SLMA) for 2012 envisioned by its President, Professor Vajira H. W. Dissanayake, A series of symposiums on e-Health were held together with the regional conferences of the SLMA in 2012.

\section{Jaffna}

The first such symposium was held in Jaffna on January 29, 2013. The symposium was held at the Jaffna Library Auditorium and was well attended with over 100 participants. The participants ranged from Administrative Officers, Specialists, Medical Officers and Field staff from the Northern Province. There was also a stall conducted by the Health Informatics Society of Sri Lanka in which some of the e-Health solutions produced by Medical Officers of Health Informatics were demonstrated in parallel to the symposium.

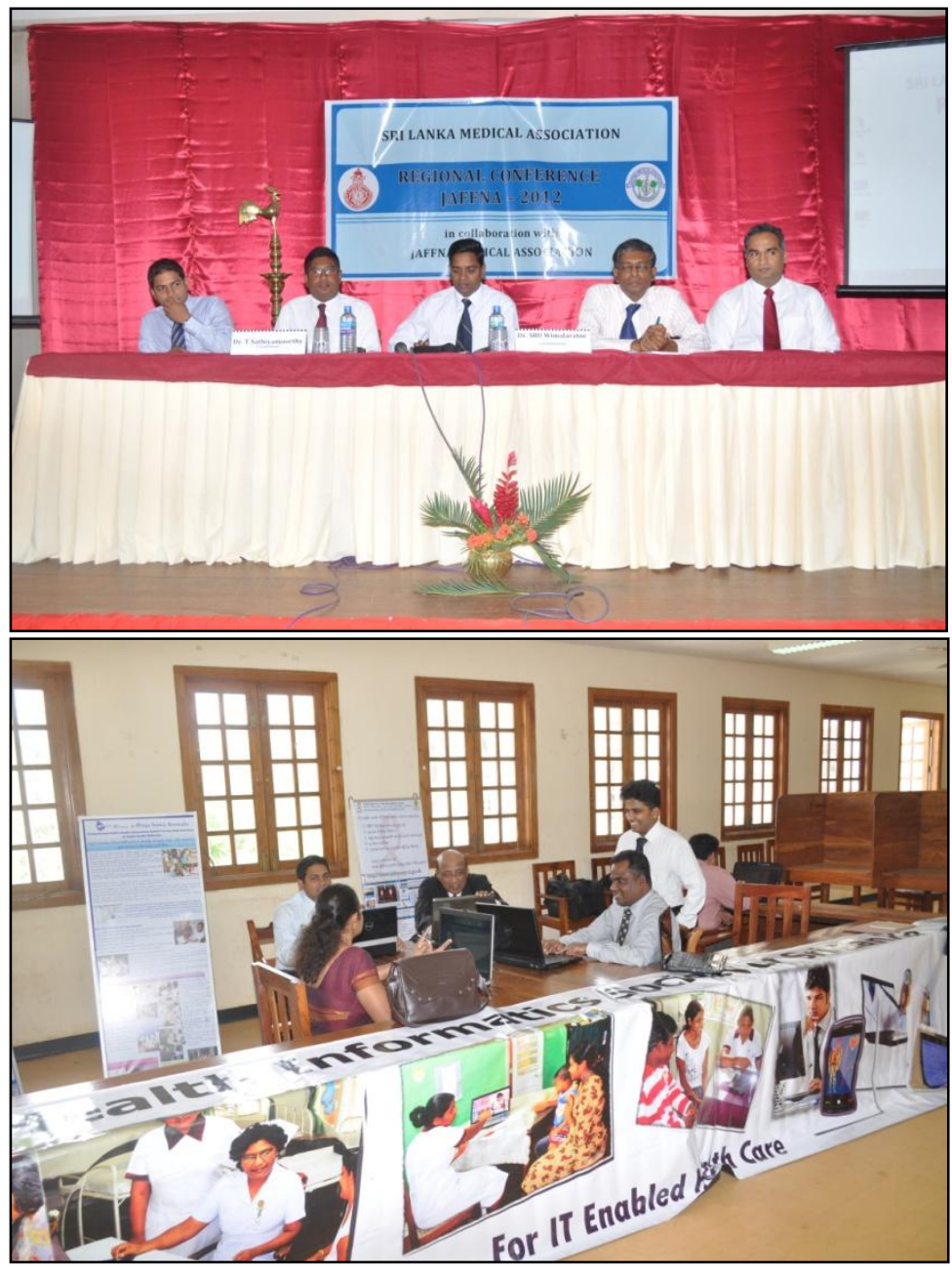

Figure 1. Dr. Clive James, Dr. Pradeep Sylva, Dr. Shivanathan, Dr. SRU Wimalarathne, Mr. Indika Soysa at the head table in the Symposium in Jaffna.

Figure 2. The HISSL stall at the Conference in Jaffna. 
The symposium was divided into three main areas. The first focused on giving an introduction to e-Health and the process of streamlining its implementation in the health sector of Sri Lanka. The second included e-Health initiatives already undertaken in the Sri Lankan health sector. The third focussed on hands on training on some of the e-Health applications already initiated.

A very comprehensive introduction to e-Health was given initially with further elaboration on many aspects of healthcare where ICT could be incorporated. This was followed by a presentation stressing the need to streamline e-Health activities. It was mentioned that there were many e-Health activities undertaken in Sri Lanka which was commendable but it was clear that they had to be coordinated from a central point. Several examples of e-Health failures around the world which occur due to the lack of coordination were discussed and it was stressed that we should learn from such mistakes and take necessary action so they do not occur in Sri Lanka. The proposed solution to streamline e-Health activities was also presented in the form of the three National e-Health Base documents.

- National e-Health Policy

- National e-Health Standards and Guidelines

- National e-Health Strategic Plan

A guest presentation was done by Mr. Atul Bengeri, Industry Manager, South Asia, Intel Corp. He stressed on the business value that e-Health could bring to us and showed many successful e-Health activities around the world. The second part of the symposium started with the presentation of one of the most successful e-Health projects implemented in Sri Lanka, The electronic Indoor Morbidity and Mortality Registry (eIMMR). This also included an online demo of the system. Thereafter, systems like the Public Health Information system and the Health Management Information System which is being implemented in 17 hospitals in the Northern and Eastern provinces were presented.

The final session of the symposium was the most sought after with many in the audience actively participating. This was a hands - on session on some of the best e-Health projects being implemented or piloted in Sri Lanka. The most commendable fact was that all these projects were the products of some of the Medical Officers who have completed the MSc in Biomedical Informatics from the Post Graduate Institute of Medicine, University of Colombo. Most of the Medical Officers who were present were keen on getting 'hands on' with the Electronic Health Records Systems for General Practitioners and the e-IMMR system. The field midwives who were present at the symposium were very interested and were actively involved with the Public Health Information System at the Medical Officer of Health (MOH) level.

The symposium was welcomed as it was the first of its kind in the Northern Province. The audience were surprised by the e-Health initiatives undertaken in Sri Lanka and were willing to be a part of it.

\section{Galle}

The second of such symposia was held at the Light House Hotel in Galle during SLMA's Southern Regional Conference. The symposium was held on the last day of the two day regional conference as a workshop on February 24, 2012. It was decided to give more prominence to the efforts undertaken in the introduction of ICT in the field of Public Health. Invitations were sent out to every Medical Officer of Health (MOH) and two Midwifes 
working under each $\mathrm{MOH}$ in the Southern Province. Participation was overwhelming, again the number of participants exceeded 100 which was dominated by MOHs and Midwifes from the southern province.

The Symposium was declared open with the welcome address of Prof. Vajira H. W. Dissanayake. This was followed by the talks on eHealth by different speakers. A special presentation was done by Mr. Atul Bengeri, Manager, South Asia - Healthcare, Intel on what could the future be with the incorporation of ICT into the Healthcare sector.

This was followed by presentations on the implementation of eHealth activities in Sri Lanka and also the focus given in streamlining them. The initiatives such as the "Public Health Information System at MOH Level" were highlighted to emphasise on the impact ICT could have on Public Health. The symposium was drawn to closure with a very lengthy and healthy discussion with the participation of the Minister of Health, Hon. Maithreepala Sirisena who also distributed certificates of participation to the MOHs and Midwives.

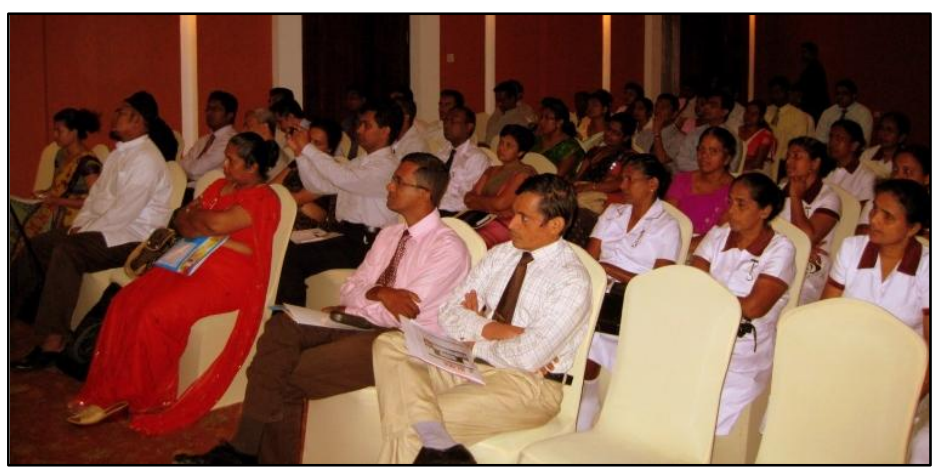

Figure 3. Participants at the eHealth Workshop held in Galle

\section{Kandy}

The third such symposium was held in the hill capital of the country during SLMA's central regional meeting, on the May 19, 2012. The programme was very similar to the previous ones but the audience was different and included many health administrators in the central province. The awareness created had increased to the level that there were some representatives of software vendors from Sri lanka and India

With increased awareness on eHealth, the discussions were now getting lengthier and healthier. This was very evident at the Symposium in Kandy where the Medical Professionals were questioning about various aspects of e-Health implementation in depth.

\section{Colombo}

The biggest and the most anticipated event in SLMA's calendar, was SLMA's $125^{\text {th }}$ Anniversary International Medical Congress. Due to the efforts of Prof. Vajira H. W. Dissanayake we were quite privileged to hold a one day workshop during the sessions. The eHealth symposium was held on the July 6,2013 . The programme was quite similar to the previous ones with slight changes. The three main sessions remained the same, which were Introduction to eHealth, Streamlining eHealth, Current eHealth Initiatives in Sri Lanka. 
The workshop had an unexpected participation of more than 200 participants, which not only included persons from the Health care sector but many from the ICT sector as well. There were many senior Healthcare Professionals who gave their whole hearted support to implementation of ICT in the healthcare sector in Sri Lanka and wished all persons involved the best of luck.

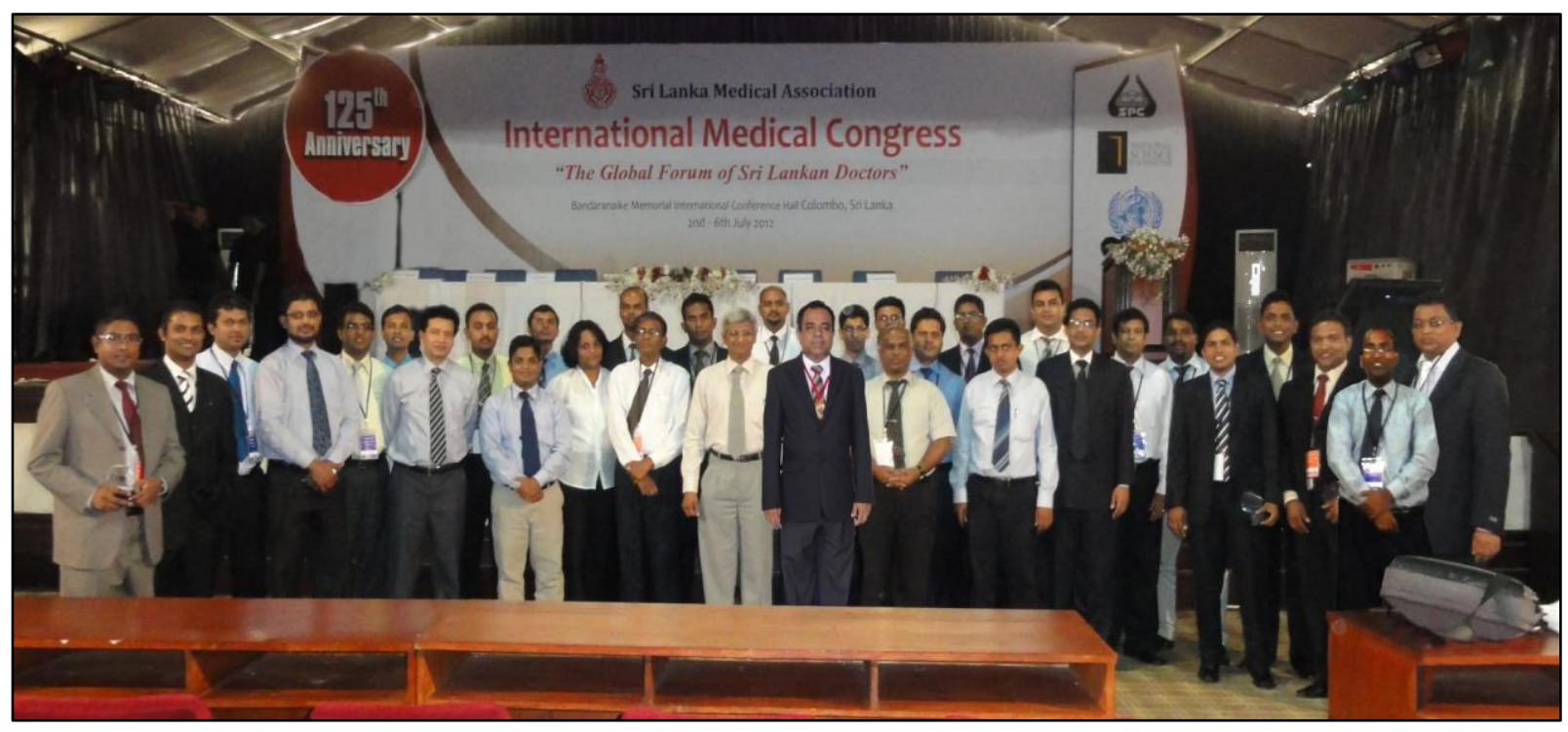

Figure 4. Group photograph of the Biomedical Informatics Graduates and the Members of the Speciality Board in Biomedical Informatics taken after the symposium held in Colombo

The end of this symposium brought to close a wonderful eHealth awareness drive that was undertaken in Sri Lanka during the year of 2012. Starting in Jaffna, going to Galle, Kandy and then finally ending up in Colombo was a really fantastic experience to all the speakers including myself. A smaller follow up meeting to this symposium was held during the Foundation Sessions of the SLMA on November 11, 2013 where all participants agreed that a firm foundation had been crucial for eHealth in Sri Lanka.

I as the coordinating officer of these symposia would like to thank Prof. Vajira H. W. Dissanayake - President SLMA, Dr. Lasantha Malavige - Secretary SLMA, Dr. S.R.U Wimalaratne - Director, Health Information, Ministry of Health, Mr. Indika De Soysa, Country Manager, Sri Lanka, Intel Corporation, all the speakers and the Biomedical Informatics Graduates who gave a lending hand for contributing immensely to the success of these symposia. 